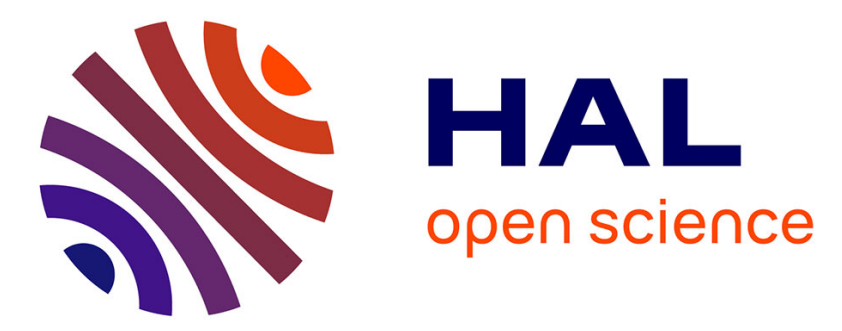

\title{
Sphinganine and sphingosine levels and ratio in urine and blood samples from a Catalonian population (Spain).
}

German Cano Sancho, S. Marin, V. Sanchis, C. Colom, M.B. Coronel, A.J. Ramos

\section{To cite this version:}

German Cano Sancho, S. Marin, V. Sanchis, C. Colom, M.B. Coronel, et al.. Sphinganine and sphingosine levels and ratio in urine and blood samples from a Catalonian population (Spain).. Food Additives and Contaminants, 2011, 28 (8), pp.1. 10.1080/19440049.2011.576437 . hal-00713059

\section{HAL Id: hal-00713059 https://hal.science/hal-00713059}

Submitted on 29 Jun 2012

HAL is a multi-disciplinary open access archive for the deposit and dissemination of scientific research documents, whether they are published or not. The documents may come from teaching and research institutions in France or abroad, or from public or private research centers.
L'archive ouverte pluridisciplinaire HAL, est destinée au dépôt et à la diffusion de documents scientifiques de niveau recherche, publiés ou non, émanant des établissements d'enseignement et de recherche français ou étrangers, des laboratoires publics ou privés. 


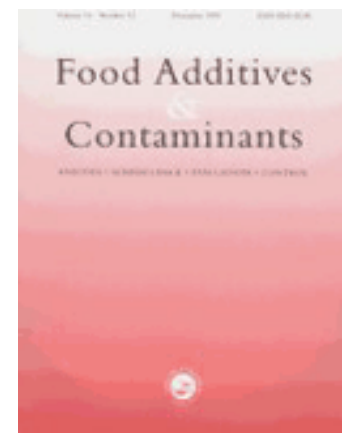

\section{Sphinganine and sphingosine levels and ratio in urine and blood samples from a Catalonian population (Spain).}

\begin{tabular}{|c|c|}
\hline Journal: & Food Additives and Contaminants \\
\hline Manuscript ID: & TFAC-2010-394.R1 \\
\hline Manuscript Type: & Original Research Paper \\
\hline $\begin{array}{r}\text { Date Submitted by the } \\
\text { Author: }\end{array}$ & 28-Feb-2011 \\
\hline Complete List of Authors: & $\begin{array}{l}\text { Cano-Sancho, German; University of Lleida, Food Technology } \\
\text { Marín, Sonia; University of Lleida, Food Technology } \\
\text { Sanchis, Vicent; University of Lleida, Food Technology } \\
\text { Colom, Carme; University of Lleida, Food Technology } \\
\text { Coronel, Maria Bernarda; University of Lleida, Food Technology } \\
\text { Ramos, Antonio; University of Lleida, Food Technology }\end{array}$ \\
\hline Methods/Techniques: & Chromatography - HPLC, Exposure assessment \\
\hline Additives/Contaminants: & Fumonisins \\
\hline Food Types: & Beer, Cereals \\
\hline Abstract: & $\begin{array}{l}\text { Fumonisins occur mainly in maize, and produce alterations on } \\
\text { sphingolipid metabolism, unbalancing sphinganine (Sa) / } \\
\text { sphingosine (So) ratio. This alteration has been proposed as a } \\
\text { biomarker of fumonisin exposure. } \\
\text { The objective of the present work was to study the urinary and } \\
\text { plasmatic levels of Sa, So as well as, the ratio Sa/So from a sample } \\
\text { of Catalonian population exposed at low levels of fumonisins. } \\
\text { Firstly, plasmatic and urinary Sa and So levels and the ratio Sa/So } \\
\text { were compared between two population groups, and after, urinary } \\
\text { Sa and So levels from corn-food consumers and a control group } \\
\text { were monitored during two weeks under controlled intake of corn- } \\
\text { foods. Sa and So levels were determined in urine and blood } \\
\text { samples using validated methods using HPLC with fluorescence } \\
\text { detection. } \\
\text { Significant differences were not found in urine samples when Sa/So } \\
\text { ratios were compared from corn-food consumers and non }\end{array}$ \\
\hline
\end{tabular}


consumers, while significant differences were found in urine and plasma samples but evidences of mechanism of action of fumonisins were not apparent. Through time-course study, we have narrowed down the day in which the maximum alteration of Sa/So ratio should be expected in humans. In this paper we have reported some useful information to improve the design of studies to validate the ratio $\mathrm{Sa} / \mathrm{So}$ as a possible biomarker of fumonisin exposure.

\section{SCHOLARONE ${ }^{m}$}

Manuscripts 


\title{
Sphinganine and sphingosine levels and ratio in urine and blood samples from a Catalonian population (Spain).
}

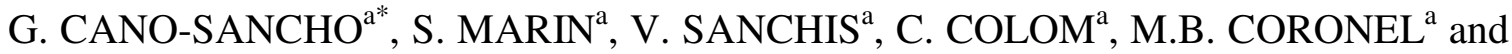
A.J. RAMOS

*Corresponding author: German Cano-Sancho. Food Technology Department, University of Lleida, Rovira Roure 191, 25198, Lleida. Telephone number: (+0034) 973702535. Fax number: (+0034) 973702596. E-mail address: gcano@tecal.udl.cat

\author{
${ }^{1}$ Food Technology Department, University of Lleida, XaRTA-UTPV, Lleida, Spain; \\ Rovira Roure 191, 25198.
}

Keywords: fumonisin; biomarker; sphinganine; sphingosine; urine; blood.

\begin{abstract}
Abbreviations: Enzyme Ceramide (CER), Food and Agriculture Organization (FAO), Food and Drug Administration (FDA), food frequency questionnaire (FFQ), fumonisin $\mathrm{B}_{1}\left(\mathrm{FB}_{1}\right)$, fumonisin $\mathrm{B}_{2}\left(\mathrm{FB}_{2}\right)$, total fumonisins $\left(\mathrm{FB}_{\mathrm{T}}\right)$, high performance liquid cromatography (HPLC), International Agency for Research on Cancer (IARC), Joint FAO/WHO Expert Committee on Food Additives (JECFA), limit of detection (LOD), limit of quantification (LOQ), non observed effect level (NOEL), o-phthaldialdehyde (OPA), provisional maximum tolerable daily intake (PMTDI), three days dietary record (R3), sphinganine (Sa), sphingosine (So), World Health Organization (WHO).
\end{abstract}




\begin{abstract}
Fumonisins occur mainly in maize, and produce alterations on sphingolipid metabolism, unbalancing the sphinganine (Sa) / sphingosine (So) ratio. This alteration has been proposed as a biomarker of fumonisin exposure. The objective of this study was to establish the urinary and plasmatic levels of $\mathrm{Sa}$, So as well as, the ratio $\mathrm{Sa} / \mathrm{So}$ from a sample of Catalonian population exposed to fumonisins at low levels. Firstly, plasma and urinary $\mathrm{Sa}$ and $\mathrm{So}$ levels and the ratio $\mathrm{Sa} / \mathrm{So}$ were compared between two population groups, and after, urinary Sa and So levels from corn-food consumers and a control group were monitored for two weeks under controlled intake of corn-foods. Sa and So levels were determined in urine and blood samples using validated methods using HPLC with fluorescence detection. Significant differences were not found in urine samples when $\mathrm{Sa} / \mathrm{So}$ ratios were compared from corn-food consumers and non-consumers, while significant differences were found in urine and plasma samples but evidence of the mechanism of action of fumonisins was not apparent. Through a time-course study, we have narrowed down the day in which the maximum alteration of $\mathrm{Sa} / \mathrm{So}$ ratio should be expected in humans. In this paper we have reported some useful information to improve the design of studies to validate the ratio $\mathrm{Sa} / \mathrm{So}$ as a possible biomarker of fumonisin exposure.
\end{abstract}




\section{Introduction}

Fumonisin $\mathrm{B}_{1}\left(\mathrm{FB}_{1}\right)$ and $\mathrm{B}_{2}\left(\mathrm{FB}_{2}\right)$ are mycotoxins produced by Fusarium verticillioides and $F$. proliferatum that commonly contaminate maize (Nelson et al. 1992). Fumonisins occur mainly in maize and maize-based foods, thus populations with high maize consumption can be exposed to significant amounts of these mycotoxins via the ingestion of fumonisin contaminated maize (Marasas 1996; Shephard et al. 1996; Visconti et al. 1996).

Acute and chronic toxicity of fumonisin has been demonstrated in several animal species, including carcinogenicity and cardiovascular toxic effects (Gelderblom et al. 1988, 1991; Howard et al. 2001; Shephard et al. 2007). $\mathrm{FB}_{1}$ is a potent cancer promoter in rats after initiation with diethylnitrosamine and aflatoxin $B_{1}$ (Gelderblom et al. 1996). Human exposure to fumonisin contaminated commodities has been correlated with high rates of esophageal and liver cancer in South Africa and China (Sydenham et al. 1990; Yoshizawa et al. 1994) and more recently, with neuronal tube defects on the TexasMexico border with other possible risk factors (Hendricks et al. 1999).

Based on toxicological evidence, the International Agency for Research on Cancer (IARC) classified $\mathrm{FB}_{1}$ as a possible human carcinogen (group 2B) (IARC 2002). The Joint FAO/WHO Expert Committee on Food Additives (JECFA) evaluated fumonisins and allocated a provisional maximum tolerable daily intake (PMTDI) of $2 \mu \mathrm{g} / \mathrm{kg}$ body 
weight/day of fumonisins. This value was determined on the basis of the overall non observed effect level (NOEL) of $0.2 \mathrm{mg} / \mathrm{kg}$ body weight/day for renal toxicity in rats, and the safety factor was 100 (JECFA 2001).

Natural occurrence of fumonisins in maize or maize-based foods has been widely studied worldwide (Castelo et al., 1998) and several surveys have been conducted in maize-food for human consumption marketed in Spain (Sanchis et al. 1994, 1995; Torres et al. 1998; Castellá et al. 1999; Velluti et al. 2001; UdL-ACSA 2009). In the latest study conducted in Catalonia to assess the incidence of mycotoxins in food for human consumption, 928 samples were purchased from the Catalonian market (in 2008 and 2009) and pooled in 370 composite samples to be analyzed. The commodities analyzed were beer, sweet-corn, corn snacks, corn flakes, free-gluten pasta and bread and ethnic food. The authors reported that the highest occurrence of fumonisins was found in beer (90\% of positive samples), however those levels were low, while the incidence of these mycotoxins in other cereal-based foods was moderated. The mean values of positive samples of corn snacks and corn flakes were $119.1 \pm 83.1$ and $78.9 \pm 27.9 \mu \mathrm{g} / \mathrm{kg}$, respectively (UdL-ACSA 2009).

Fumonisins have a remarkable structural similarity to sphingolipids (Merrill and Sweeley 1996; Riley et al. 2001). This group of mycotoxins, especially $\mathrm{FB}_{1}$, potently inhibits the enzyme ceramide (CER) synthase which catalyzes the acylation of sphinganine (Sa) and reacylation of sphingosine (So). The inhibition of CER synthase increases the intracellular Sa and other sphingoid bases, highly cytotoxic compounds. This imbalance 
has been proposed as the main responsible for the toxicity, and possibly carcinogenicity, of FBs, based on mechanistic studies with cells cultures, and borne out by animal studies (Wang et al. 1991; Norred et al. 1992; Merrill et al. 1993, 2001; Yoo et al. 1996; Riley et al. 2001; Voss et al. 2006; Zitomer et al. 2009). Based on this biological perturbation, elevation of $\mathrm{Sa}$ to So in tissues, urine and blood have been proposed as potential biomarkers of fumonisin exposure in various animal species (Wang et al. 1992; Riley et al. 1993; Morgan et al. 1997; Wang et al. 1999; van der Westhuizen et al. 2001; Kim et al. 2006; Tran et al. 2006; Cai et al. 2007). Several studies have been conducted to assess the effectiveness of this biomarker in humans, but results did not allow an accurate validation (Hendricks et al. 1999; van der Westhuizen et al. 1999, 2008, 2010; Abnet et al. 2001; Qiu and Liu 2001; Solfrizzo et al. 2004; Nikiema et al. 2008; Silva et al. 2009; $\mathrm{Xu}$ et al. 2010). The individual Sa and So basal levels, as well as, the basal Sa/So ratio vary depending on unknown parameters, being related with nutrition factors (Abnet et al. 2001; Shephard et al. 2007). The sensitivity of the correlation between fumonisin intake and $\mathrm{Sa} / \mathrm{So}$ has been demonstrated to be poor at low and very low doses in animals $(<1$ $\mathrm{mg} / \mathrm{kg}$ bw/day). Considering that the PMTDI is $2 \mu \mathrm{g} / \mathrm{kg}$ bw/day, low sensitivity should be expected when we apply this biomarker in human population (Kim et al. 2006; Voss et al. 2006; Cai et al. 2007).

The objective of the work reported here was to study the urinary and plasma levels of Sa, So as well as the ratio $\mathrm{Sa} / \mathrm{So}$ from a sample of Catalonian population, exposed at low levels of fumonisins, as a means to assess this ratio as a possible biomarker of fumonisin intake in the region. This work is structured in two experimental sections: in the first, 
plasma and urinary Sa and So levels and the ratio Sa/So were compared between two population groups, in the second, urinary Sa and So levels from maize-food consumers and a control group were monitored during two weeks under controlled intake of maizefoods.

\section{Materials and methods}

Study design and sampling

This research project did not involve any risks for the volunteer donors; neither harmful modification of usual dietary habits nor administration was included in methodology for the subjects. Each participant was informed about the study rules and a signed authorization was requested individually.

\section{Part 1. Urinary and plasmatic Sa/So ratio point estimates.}

The first attempt to know the urinary and plasmatic Sa and So levels, and the ratio Sa/So from Catalonian population was designed to compare $\mathrm{Sa}$, So levels and ratio $\mathrm{Sa} / \mathrm{So}$ between high consumers of maize food and low/non consumers.

Part 1.1. Study of plasmatic sphingoid bases levels

Blood samples were collected from 136 healthy adult volunteers during 2008, from Catalonian population following approval from University of Lleida Ethical Council and informed consent. Blood was extracted and stored (less than 2 hours) in Vacutainers ${ }^{\circledR}$ with anticoagulant (EDTA) followed by centrifugation at $1000 \mathrm{~g}$ for $10 \mathrm{~min}$, and finally, the plasma was stored at $-20^{\circ} \mathrm{C}$ until analysis (same month). Maize-food intake was requested with a Food Frequency Questionnaire (FFQ) in order to determine the 
approximate individual fumonisin intake. Fumonisin intake was estimated through the combination of the consumption data with contamination data provided by UdL-ACSA (2009). Two population groups were made depending on their estimated fumonisin intake: high exposed and low or none exposed.

\section{Part 1.2. Urinary sphingoid base levels}

First morning urine from 89 volunteers was collected in sterile containers, during 2009, according to Declaration of Helsinki. Urine samples were transported under refrigeration and they were stored at $-20^{\circ} \mathrm{C}$ until analysis. In order to estimate the individual fumonisin intake, maize-food intake was requested through a FFQ and a 3 days record (R3) during the days prior to the sample collection day. Fumonisin intake was estimated through the combination of the consumption data with contamination data provided by UdL-ACSA (2009). The population was grouped in high consumers and low consumers depending on their maize dietary estimates. Finally, 7 urine samples were provided by esophageal cancer sufferers from University Hospital Arnau de Vilanova (Lleida). These samples were analyzed to determine Sa and So levels, and compared with the healthy group.

\section{Part 2. Study of the urinary Sa and So time-course.}

To know the changes of urinary sphingolipid levels over time, two groups of volunteers were monitored during 16 days. One group was composed of maize-food consumers (exposed group $n=24$ ), and the other, by non consumers (control group $n=12$ ). The exposed group was restricted of maize-food consumption during 16 days, with the exception of the seventh day after restriction, when the maize-food intake was completely 
free. The food items consumed were: home-made Mexican "tortillas", corn snacks, maize-based cake, sweet corn and beer purchased from a Catalonian market. A representative sample of each maize-food consumed during that day, was kept and they were analyzed by duplicated to determine the FB levels. The control group was restricted to maize-food during the entire study period (See Fig 1).

[Insert Figure 1 about here, if possible]

( Title: Fig. 1. Diagram of urine sampling design and restriction periods performed in the study to assess urinary Sa and So time-course.

Footnote: US: urine sample, R24: 24 hours record, FFQ: Food Frequency Questionnaire).

At the beginning of the experiment, dietary habits of the individuals were requested via a FFQ. Maize-food intake during the free consumption day (day 0) by the exposed group was requested with a 24 hour dietary using household sizes previously standardized. First morning urine was sampled according to Declaration of Helsinki, from control group at days $-7,0,4$ and 8, while in the exposed group, two sampling days (1 and 6) were added in order to increase the accuracy. Urine samples were transported under refrigeration, and they were stored at $-20^{\circ} \mathrm{C}$ until analysis (during the same month). Sa and So levels were determined for each urine samples.

Fumonisin analysis in food

Fumoniprep $^{\circledR}$ immunoaffinity cleanup columns (IAC) (R-Biopharm, Rhône LTD Glasgow, UK) were used to extract $\mathrm{FB}_{1}$ and $\mathrm{FB}_{2}$ from beer samples. A volume of $5 \mathrm{~mL}$ 
of beer previously degassed in ultrasonic bath during 40 minutes was mixed with $15 \mathrm{~mL}$ of phosphate buffer solution (PBS; $0.8 \% \mathrm{NaCl}, 0.12 \% \mathrm{Na}_{2} \mathrm{HPO}_{4}, 0.02 \% \mathrm{KH}_{2} \mathrm{PO}_{4}, 0.02 \%$ $\mathrm{KCl})$ and drained through the IAC. The column was washed with $20 \mathrm{~mL}$ of PBS solution and fumonisins were eluted with $1.5 \mathrm{~mL}$ of methanol grade HPLC and $1.5 \mathrm{~mL}$ of milli-Q water. Regarding solid maize-based samples, $10 \mathrm{~g}$ of ground sample was mixed with $1 \mathrm{~g}$ $\mathrm{NaCl}$, and $50 \mathrm{~mL}$ of extract solution (50\% water, $25 \%$ methanol, $25 \%$ acetonitrile) for 20 minutes and filtered. $10 \mathrm{~mL}$ of filtered solution was diluted with $40 \mathrm{~mL}$ of PBS and drained through the IAC and follows as described previously.

Fluorescent derivatives of $\mathrm{FB}_{1}$ and $\mathrm{FB}_{2}$ were obtained using pre-column derivatization with an $o$-phthaldialdehyde (OPA) solution prepared diluting $40 \mathrm{mg}$ of $o$ phthaldialdehyde with $1 \mathrm{~mL}$ of methanol HPLC grade and mixed with $5 \mathrm{~mL}$ of $\mathrm{Na}_{2} \mathrm{~B}_{4} \mathrm{O}_{7} \cdot 10 \mathrm{H}_{2} \mathrm{O}(0.1 \mathrm{M})$ and $50 \mu \mathrm{L}$ de 2 -mercaptoethanol. Derivatization was conducted mixing $200 \mu \mathrm{L}$ of eluate with $200 \mu \mathrm{L}$ of OPA solution for 30 seconds in vortex. Chromatography equipment: Separations Module Alliance 2695 Waters ${ }^{\circledR}$, analytical column Waters Spherisorb® $5 \mu \mathrm{m}$ ODS2, 4.6 x $150 \mathrm{~mm}$, Multi $\lambda$ Fluorescence Detector Waters $2475^{\circledR}$, kept at $35^{\circ} \mathrm{C}$ and a flow-rate maintained at $1 \mathrm{~mL} / \mathrm{min}$. Mobile phase was based on a methanol and $0.1 \mathrm{M}$ sodium dihydrogen phosphate $(77: 23$, v/v) solution. Excitation and emission wavelength was $335 \mathrm{~nm}$ and $440 \mathrm{~nm}$, respectively.

Sphinganine and Sphingosine analysis in plasma

Plasma $(500 \mu \mathrm{L})$ was deproteinized with methanol $(2 \mathrm{~mL})$ and the protein precipitate was centrifuged down at $1200 \mathrm{~g}$ for $10 \mathrm{~min}$ at $10^{\circ} \mathrm{C}$. An aliquot of the sobrenatant $(1.5 \mathrm{~mL})$ was mixed with $1.5 \mathrm{~mL}$ potassium chloride solution $(0.8 \%)$ and $50 \mu \mathrm{L}$ potassium 
hydroxide $(1 \mathrm{M})$. The mixture was extracted with $4 \mathrm{~mL}$ of ethyl acetate by gentle rotation in a blender for $20 \mathrm{~min}$ and the phases were separated by centrifugation at $1100 \mathrm{~g}$ for 15 min, as described by Castegnaro et al. (1998). The organic phase was evaporated to complete dryness at $55^{\circ} \mathrm{C}$ under nitrogen. Dried samples were redissolved by vortex shaking in $275 \mu \mathrm{L}$ methanol-water solution (88:12) and derivatized for $35 \mathrm{~min}$ by addition of $25 \mu \mathrm{L}$ of OPA mixture. The derivatization mixture consisted of $50 \mathrm{mg}$ OPA dissolved in $1 \mathrm{~mL}$ of ethanol and mixed with $50 \mu \mathrm{L}$ of mercaptoethanol and $48.95 \mathrm{~mL}$ of boric acid solution ( $3 \%$ ) adjusted to $\mathrm{pH} 10.5$ with potassium hydroxide $(1 \mathrm{M})$ to obtain a final volume of $50 \mathrm{~mL}$. The derivatives were analyzed by HPLC with fluorescence detection (excitation wavelength of $340 \mathrm{~nm}$, emission wavelength of $455 \mathrm{~nm}$ ), using a Waters Spherisorb ${ }^{\circledR} 3 \mu \mathrm{m}$ ODS2 $4.5 \times 250 \mathrm{~mm}$ column, kept at $35^{\circ} \mathrm{C}$ and a flow-rate maintained at $1 \mathrm{~mL} / \mathrm{min}$ of methanol-water $(88: 12, \mathrm{v} / \mathrm{v})$.

Sphinganine and sphingosine analysis in urine

Urinary samples were stored at $-20^{\circ} \mathrm{C}$ in the dark before the analysis. Extraction of $\mathrm{Sa}$ and So was performed using a method adapted from Castegnaro et al. (1996). To sum up, 20 $\mathrm{mL}$ of urine thawed sample were centrifuged at $2000 \mathrm{~g}$ for 15 minutes at $10{ }^{\circ} \mathrm{C}$, in order to isolate exfoliated cells. Cell pellets were re-suspended in $2 \mathrm{ml}$ distilled water with 50 $\mu \mathrm{l}$ of potassium hydroxide $(1 \mathrm{M})$. Following, $2 \mathrm{ml}$ of ethyl acetate were added and mixed vigorously using the vortex for 1 minute. Then, the mixture was centrifuged at $2000 \mathrm{~g}$ for 15 minutes, and the upper solvent layer was kept, while the aqueous phase was extracted again. Finally, the mixed solvent layers containing sphingolipids were dried under a 
nitrogen stream. Dried samples were analyzed as described for plasma samples, under the same chromatographic conditions.

\section{Validation of the analytical methods}

The analytical methods used for fumonisins, Sa and So were assessed for selectivity, linearity, and precision. Selectivity was checked by injecting $50 \mu \mathrm{l}$ of mycotoxin standard solutions three times before injecting extracted samples and comparing the peak retention times and the fluorescence spectra of the substances that produced these peaks. Standard curves were generated by linear regression of peak areas against concentrations.

Accuracy and recovery were established by determination of $\mathrm{FB}_{1}$ and $\mathrm{FB}_{2}$ levels, spiked in samples of corn snacks, beer, and sweet corn; in the case of Sa and So, they were spiked in urine and blood samples. Recovery was determined by comparing the absolute responses of fumonisins, Sa and So, with the absolute responses of calibration standards. The limit of detection (LOD) was considered as the mycotoxin and the sphingolipid concentration that provides a signal equal to $\mathrm{b}+3 \mathrm{Sb}$, where $\mathrm{b}$ is the intercept of the calibration curve and $\mathrm{Sb}$ is the standard error of the estimate assuming to be the blank, and the limit of quantification (LOQ) was considered equal to $3 \times \mathrm{LOD}$.

Recovery data, repeatability, limit of detection (LOD) and limit of quantification (LOQ) of $\mathrm{FB}_{1}$ and $\mathrm{FB}_{2}$ in sweet corn, corn snacks and beer are shown in Table 1. These values are in accordance to performance criteria established by Commission Regulation (EC) $\mathrm{N}^{\mathrm{o}}$ 401/2006 (European Commission 2006a).

[Insert Table 1 about here, if possible] 
Method performance characteristics for Sa and So in blood are shown in Table 2. This method showed recovery rates of So ranging from $92.2 \pm 19.7$ to $104.0 \pm 12.8 \%$, while the recovery rates for Sa were between $93.1 \pm 13.4$ and $98.3 \pm 11.2 \%$.

[Insert Table 2 about here, if possible]

The method to determine the sphingoid bases in urinary samples was optimized in order to obtain a low detection limit, due to the low concentration of sphingolipids expected to be found in this matrix. Recovery rates, RSDr, LOQ and LOD are shown in Table 3.

[Insert Table 3 about here, if possible]

\section{Statistical Analysis}

$\mathrm{Sa} / \mathrm{So}$ ratios were calculated individually by division of $\mathrm{Sa}$ and So levels from each volunteer, and expressed as medians, means and standard deviations of ratios for each group.

Mann-Whitney $U$ test was used for two-group comparison and Kruskal-Wallis test was used to compare more samples. Principal Component Analysis was conducted to obtain matrix correlation from Sa/So ratio data and associated factors. Software SAS Enterprise guide v2.0.0.417 ${ }^{\circledR}$ and SAS v9.0. ${ }^{\circledR}$ were used in statistical analysis.

\section{Results}


Study of sphingoid base levels and ratios in plasma

In this first study, 136 blood donors were grouped in high maize-based food consumers (68) and non consumers (68). The mean exposure to fumonisin estimated for the first group was $0.23 \pm 0.11 \mu \mathrm{g} / \mathrm{kg}$ bw/day. Medians were 0.53 and 0.46 for maize-based food consumers and non consumers, respectively. Although significant differences were observed when the Sa/So ratios were compared, non statistically significant differences were found between sphinganine levels $(P>0.05)$, the sphingosine decrease being the most probable responsible of ratio variation in the exposed group (See Table 4).

Study of the sphingoid base levels and ratios in urine

In this cross-sectional study, 78 volunteers were selected to assess the urinary Sa and So levels. Each volunteer was asked about dietary habits, through a FFQ and a R3. Considering the estimated fumonisin intake, the population was divided in high and low consumers in order to compare $\mathrm{Sa}$ and So levels and their ratios. The mean fumonisin intake estimated through the R3, was 0.013 and $0.046 \mu \mathrm{g} / \mathrm{kg}$ bw/day for males and females, respectively, while these respective estimates were 0.089 and $0.057 \mu \mathrm{g} / \mathrm{kg}$ bw/day when the estimation was made using the FFQ The most important bias sources were that males overestimated significantly the beer consumption in comparison with the R3 and the females underestimated the usual corn snacks consumption with this method.

Levels of $\mathrm{Sa}$, So and $\mathrm{Sa} / \mathrm{So}$ ratio and fumonisin intake estimated through the $\mathrm{R} 3$ are shown in the Table 4.

[Insert Table 4 about here, if possible] 
Significant differences were found between median ratios $\mathrm{Sa} / \mathrm{So}$ from high and low consumers $(P<0.05)$, but no differences were found in Sa and So levels.

The urinary samples from esophageal cancer sufferers showed mean levels of Sa and So to be $0.376 \pm 471$ and $0.208 \pm 0.484 \mathrm{ng} / \mathrm{mL}$, respectively, while the mean Sa/So ratio was $0.363 \pm 0.458$, no significantly different from that of healthy population.

\section{Urinary $\mathrm{Sa} / \mathrm{So}$ ratio time-course}

Fumonisin dietary intake of individuals was assessed combining food consumption data with fumonisin levels on the maize-food consumed. Consumption data was recorded during the day 0 (free consumption day), using previously standardized portions. Mean levels of fumonisin contamination in corn snacks, Mexican "tortillas", corn-based cake, and sweet corn samples were 133.9, 99.3, $110.1 \mu \mathrm{g} / \mathrm{kg}$ and non detectable level, respectively. These values were far from EU limits of $400 \mu \mathrm{g} / \mathrm{kg}$ (European Commission 2006b). Volunteers were classified in three groups, depending on total fumonisin intake estimated during the "free maize-food consumption day": high consumers, H, $(>0.6$ $\mu \mathrm{g} / \mathrm{kg}$ bw/day, mean $0.84 \pm 0.26 \mu \mathrm{g} / \mathrm{kg}$ bw/day); low consumers, $\mathrm{L},(<0.6 \mu \mathrm{g} / \mathrm{kg}$ bw/day, mean $0.43 \pm 0.12 \mu \mathrm{g} / \mathrm{kg}$ bw/day) and non consumers, $\mathrm{C}$, (control group, $\mathrm{n}=12$ ). The high consumers did not exceed the tolerable daily intake of $2 \mu \mathrm{g} / \mathrm{kg}$ bw/day. The volunteer population was 18 males and 18 females. $55 \%$ of volunteers presented a body mass index between 18.5 and $24.9 \mathrm{~kg} / \mathrm{m}^{2}$ (normal) and $45 \%$ were overweight. Tobacco was consumed by $32 \%$ of the individuals.

Mean levels of $\mathrm{Sa}$ and $\mathrm{So}$, and mean ratios in urine samples from volunteer donors collected during the restriction period, are shown in Table 5. The two volunteers excluded 
from the study showed So and Sa basal levels markedly higher than the rest of the group (40 fold greater than the mean group level).

[Insert Table 5 about here, if possible]

Median Sa levels at the beginning of the study were $0.27,0.28$ and $0.14 \mathrm{ng} / \mathrm{mL}$, for non consumers, low consumers and high consumers, respectively, and So median levels were 1.22, 0.68 and $0.33 \mathrm{ng} / \mathrm{mL}$, respectively. The median Sa/So ratios were quite similar between exposition groups, without statistically significant differences for these values (0.25 to 0.70$)$. During the first week of maize-food restriction, we did not observe significant differences in the Sa/So ratios for any group, however, after the free maizefood consumption day, statistically significant differences were observed in exposed groups while no differences were observed in the control group with time. The maximum increase of the $\mathrm{Sa} / \mathrm{So}$ ratio was observed the fourth day after the free consumption day, with mean values of $1.96 \pm 2.24$ and $2.52 \pm 2.00 \mathrm{ng} / \mathrm{mL}$ for low and high consumers, respectively, while the mean ratio for the control group was $0.67 \pm 0.49 \mathrm{ng} / \mathrm{mL}$ (see figure 2). After the fourth day, the stabilization of the ratios was observed for these groups, recovering initial values, without statistical differences among all groups (See Table 5). This fact was confirmed by means of the correlation matrix of the ratios against the estimated daily intake during the free consumption day. Principal component analysis of $\mathrm{Sa}, \mathrm{Sa}, \mathrm{Sa} / \mathrm{So}$ and fumonisin intake showed that the higher correlation should be expected between estimated fumonisin intake and $\mathrm{Sa} /$ So ratio from day $4(\mathrm{r}=0.3322 ; P<0.01)$ with 
low correlation with the other days. The mean $\mathrm{Sa} / \mathrm{So}$ ratios through the time are represented in the figure 2 .

[Insert Figure 2 about here, if possible]

Title: Fig. 2. Time-course of mean $\mathrm{Sa} / \mathrm{So}$ ratio for high exposed $(\mathrm{H}, \cdots \bullet \cdot)$, low exposed $(\mathrm{L},-\mathbf{n})$ and non exposed $\left(\mathrm{C}, \boldsymbol{-}^{--}\right)$.

Sa levels decreased during the first restriction week in each group, but increased after the free consumption day in exposed groups (high and low consumers), while the level slightly decreased in the control group. So levels decreased during the first week, after day 0 the median values decreased slightly but no significant differences were found (See Table 5).

The absolute modification of the sphingoid bases, as well as of the ratio, after the free consumption day was quantified as the absolute difference (maximum - minimum) among day 0 and day 8 (Table 6). Sa and So levels were slightly modified during this period, without differences among exposure groups, neither significant differences were observed in the increase of the Sa/So ratio.

[Insert Table 6 about here, if possible]

\section{Discussion}

Based on the mechanism of action, it has been observed that fumonisins inhibit CER synthase, a disruption that leads to an increase of Sa levels and Sa/So ratio (Riley et al. 
2001). It is due to the rapid elimination and low bioavailability of fumonisins, that it is necessary to find an indirect indicator of human exposure to these toxins. Sa/So and Sa 1phosphate / So 1-phosphate ratios in tissues, urine and blood, have been proposed as potential biomarkers in various animals (Wang et al. 1992, 1999; Morgan et al. 1997; van der Westhuizen et al. 2001; Tran et al. 2006), these ratios being validated in F344 rats by Cai et al. (2007), obtaining more sensitive results in urine than in serum for acute and sub-chronic exposure to $\mathrm{FB}_{1}$. However, no successful results have been found when this biomarker has been assessed in human population, due to the low sensitivity when it is applied over individuals (van der Westhuizen et al. 1999, 2008, 2010; Abnet et al. 2001; Qiu and Liu 2001; Solfrizzo et al. 2004; Nikiema et al. 2008; Silva et al. 2009; Xu et al. 2010).

In Catalonia, maize-based food is not highly consumed; therefore the exposure of the population to fumonisins is expected to be low, as reported in the Technical Report from UdL-ACSA (2009). In the present study, we have estimated that fumonisin intake of the volunteers from this region was in all cases below the PMTDI of $2 \mu \mathrm{g} / \mathrm{kg} \mathrm{bw} / \mathrm{day}$, including the high consumers, who showed maximum estimates of 1.04 and $1.42 \mu \mathrm{g} / \mathrm{kg}$ bw/day. Other previous studies were conducted in regions where maize is highly consumed, and estimated fumonisin intake has been estimated to be quite high; for example, in some regions of South Africa the mean fumonisin intake was estimated to be between 5.8 and $3.8 \mu \mathrm{g} / \mathrm{kg}$ bw/day (van der Westhuizen et al. 1999, 2008, 2010), and the $93 \%$ of 43 volunteers from Huian (China) had their daily FB intakes above the PMTDI of $2 \mu \mathrm{g} / \mathrm{kg}$ bw/day (Xu et al. 2010). 
Concerning our cross-sectional studies, the mean plasmatic Sa and So levels were higher than urinary levels, as reported previously (van der Westhuizen et al. 2008), while mean ratios were slightly higher in urinary samples.

In both cross-sectional studies we have found significant differences between ratios from exposed and non exposed groups, however no differences were found in sphinganine levels. In the study performed with plasma, the main responsible of ratio increase was elucidated through a decrease of So levels, with significant differences, therefore no evidences of mechanism of action of fumonisins were found.

Esophageal cancer rates have been correlated with fumonisin exposure in China and South Africa, to regions highly exposed to fumonisins (Chu and Li 1994; Zhang et al., 1999; Wang et al., 2000; Rheeder et al., 1992). In northern Italy region, maize consumption was correlated with higher rates of esophageal cancer than other regions (Rossi et al., 1982; Franceschi et al., 1990), and presence of fumonisin-producing Fusarium species in maize and polenta was lately reported (Logrieco et al., 1995; Pascale et al., 1995). In this study seven urine samples from esophageal cancer sufferers were analyzed and compared with healthy groups, and non differences were found in any case.

In our latest study, we have monitored the expected alteration of Sa and So levels in urine from maize-food consumers after a free maize-food consumption day within a maizefood restriction period. Significant differences were observed for the ratio Sa/So after the free consumption day (day 0) for both exposed groups, while no differences were observed in the control group. The maximum values of the ratios were observed at day 4 after the free consumption day. Previous studies conducted with animal species dosed with fumonisins showed variable results concerning the day of maximum $\mathrm{Sa} / \mathrm{So}$ ratio. For 
example, the maximum peak of $\mathrm{Sa} / \mathrm{So}$ in weaned piglets dosed with $5 \mathrm{mg} / \mathrm{kg}$ bw/day showed the peak at $12 \mathrm{~h}$ (Dilkin et al. 2010), in rats dosed with $10 \mathrm{mg} / \mathrm{kg}$ bw/day the maximum was observed at day 3 and day 5 (Garren et al. 2001; Cai et al. 2007), while in vervet monkeys dosed with $1 \mathrm{mg} / \mathrm{kg}$ bw/day the maximum was found to be the day 3 (Van der Westhuizen et al. 2001). The time period between fumonisin intake and maximum peak of the ratio $\mathrm{Sa} / \mathrm{So}$ is an important data to validate a human biomarker that will permit a better design of sampling and dietary exposure assessment.

To date, the cross-sectional studies have shown poor correlation between fumonisin dietary intakes and $\mathrm{Sa} / \mathrm{So}$ ratio in humans, however, successful results have been found in several animal studies. Thus, there are several drawbacks which prevent this biomarker to be applied to humans for epidemiologic purposes:

1) The individual $\mathrm{Sa}$ and So basal levels, as well as, the basal Sa/So ratio vary depending on unknown parameters, being related with nutrition factors (Abnet et al. 2001; Shephard et al. 2007). Therefore, the absolute ratio could not be a good predictor of fumonisin intake.

2) The sensitivity of the correlation between fumonisin intake and Sa/So has been demonstrated to be poor at low and very low doses in animals $(<1 \mathrm{mg} / \mathrm{kg}$ bw/day). Considering that the PMTDI is $2 \mu \mathrm{g} / \mathrm{kg}$ bw/day, low sensitivity should be expected when we apply this biomarker in human population. The Sa-P and So-P have been proposed to monitore the exposure of fumonisins, being more sensitive than the original sphingoid bases, therefore, could be suitable to use in human epidemiological studies for low-level exposed population (Kim et al. 2006; Voss et al. 2006; Cai et al. 2007). 
3) To reach a realistic correlation between sphingoid base levels and fumonisin intake in human populations, it is required to use reliable analytical and consumption data (Willet 1998). Improved analytical methods to determine Sa and So are reliable in urine and blood and likewise the methods to determine the FB levels in food. However, the dietary intake assessment methods used in previous studies do not report on their accuracy or reliability.

4) Finally, the most commonly used method to assess dietary intake has been the food frequency questionnaire (FFQ); it is the most comfortable method for researchers and volunteers. If we consider that the maximum $\mathrm{Sa} / \mathrm{So}$ ratio has been closely correlated with a specific consumption day in animals (dose day) (Garren et al. 2001; van der Westhuizen et al. 2001; Dilkin et al. 2010), and reversible after that point, the dietary intake methods should assess rigorously those foods consumed 4-5 days before the urine sampling. Therefore, the dietary record could be a more accurate method to assess the fumonisin intake than de FFQ.

\section{Conclusions}

To our knowledge, this is the first study conducted in Spain to assess the sphingoid base levels and ratios in plasma and urine from a maize-food consumer population. We have proved that the volunteers were not exposed to high levels of fumonisins, in all cases below PMTDI of $2 \mu \mathrm{g} / \mathrm{kg}$ bw/day (maximum value of $1.4 \mu \mathrm{g} / \mathrm{kg}$ bw/day). The analytical method to determine Sa and So in urine and plasma was reliable, showing good recovery and reproducibility. The results showed higher $\mathrm{Sa}$ and So levels in plasma than in urine, and significant differences were shown when males were compared to females. 
Concerning Sa/So ratios from maize-food consumers and non-consumers, significant differences were found in urine and plasma samples but evidences of mechanism of action of fumonisins were not apparent. Through time-course study, we have narrowed down the day in which the maximum alteration of $\mathrm{Sa} / \mathrm{So}$ ratio should be expected in humans.

In this paper we have reported some useful information to improve the design of studies to validate the ratio $\mathrm{Sa} / \mathrm{So}$ as a possible biomarker of fumonisin exposure. However, more studies are required to better understand the use of this biomarker with human population, mainly, to improve the accuracy at low levels of exposure.

\section{Acknowledgements}

The authors would like to acknowledge Exposure Assessment of Spanish Population to Fusarium Toxins Project, National Plan of Spanish Government (AGL2008-05030-C0201), Catalonian Food Safety Agency of 'Generalitat de Catalunya' Health Department and University of Lleida for their financial support.

\section{References}

Abnet CC, Borkowf CB, Qiao Y-L, Albert PS, Wang E, Merrill AH, Mark SD, Dong ZW, Taylor PR, Dawsey SM. 2001. A cross-sectional study of human serum sphingolipids, diet and physiologic parameters. J Nutr. 131:2748-2752. 
Cai Q, Tang L, Wang J-S. 2007. Validation of fumonisin biomarkers in F344 rats. Toxicol Appl Pharmacol. 225:28-39.

Castegnaro M, Garren L, Gaucher I, Wild CP. 1996. Development of a new method for the analysis of sphinganine and sphingosine in urine and tissues. Nat Tox. 4:284-290.

Castegnaro M, Garren L, Galendo D, Gelderblom WCA, Chelule P, Dutton MF, Wild CP. 1998. Analytical method for the determination of sphinganine and sphingosine in serum as a potential biomarker for fumonisin exposure. J Chromatogr B. 720:15-24.

Castellá G, Bragulat MR, Cabañes FJ. 1999. Surveillance of fumonisins in maize-based feed and cereals from Spain. J Agr Food Chem. 47: 707-710.

Castelo MM, Summer SS, Bullerman LB. 1998. Occurrence of fumonisins in corn-based food products. J Food Prot. 61:704-707.

Chu FS, Li GY. 1994. Simultaneous occurrence of fumonisin B1 and other mycotoxins in moldy corn collected in the People's Republic of China in regions with high incidences of esophageal cancer. Appl Environ Microbiol. 60:847-852.

Dilkin P, Direito G, Simas MM, Mallmann CA, Corrêa B. 2010. Toxicokinetics and toxicological effects of single oral dose of fumonisin B1 containing Fusarium verticillioides culture material in weaned piglets. Chem Biol Interact. 185:157-62. 
European Commission. 2006a. Commission Regulation (EC) $\mathrm{N}^{\mathrm{o}}$ 401/2006 of 23 February 2006. OJEU. L70:12-34.

European Commission. 2006b. Commission Regulation (EC) $\mathrm{N}^{\mathrm{o}} 1881 / 2006$ of 19 December 2006. OJEU. L364:5-24.

Franceschi S, Bidoli E, Barón AE, La Vecchia C. 1990. Maize and risk of cancer of the oral cavity, pharynx and esophagus in northeastern Italy. J Natl Cancer Inst. 82:14071411.

Garren L, Galendo D, Wild CP, Castegnaro M. 2001. The induction and persistence of altered sphingolipid biosynthesis in rats treated with fumonisin B1. Food Addit Contam. $18: 850-6$.

Gelderblom WCA, Jaskiewicz K, Marasas WFO, Thiel PG, Hora RM, Vleggar R, Kriek NPJ. 1988. Fumonisins-Novel mycotoxins with cancer-promoting activity produced by Fusarium moniliforme. Appl Environ Microbiol. 54:1806-1811.

Gelderblom WCA, Kriek NPJ, Marasas WFO, Thiel PG. 1991. Toxicity and carcinogenecity of the Fusarium moniliforme metabolite, fumonisin $B_{1}$ in rats. Carcinogenesis. 12:1247-1251. 
Gelderblom WC, Snyman SD, Lebepe-Mazur S, van der Westhuizen L, Kriek NP, Marasas WF. 1996. The cancer-promoting potential of fumonisin $B_{1}$ in rat liver using diethylnitrosamine as a cancer initiator. Cancer Lett. 109:101-108.

Hendricks KA, Simpson JS, Larsen RD. 1999. Neural tube defects along the TexasMexico border, 1993-1995. Am J Epidemiol. 149:1119-1127.

Howard PC, Eppley RM, Stack ME, Warbritton A, Voss KA, Lorentzen RJ, Kovach RM, Bucci TJ. 2001. Fumonisin $B_{1}$ carcinogenicity in a two-year feeding study using F344

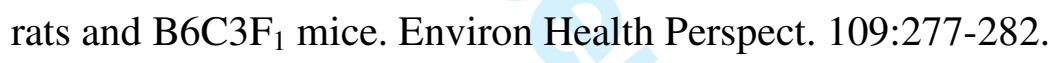

IARC (International Agency for Research on Cancer). 2002. IARC Monographs on the Evaluation of Carcinogenic Risks to Humans, vol. 82. IARC, Lyon, France, p. 301-366.

Joint FAO/WHO Expert Committee on Food Additives (JECFA). 2001. Evaluation of certain mycotoxins in food: fifty-sixth report of the Joint FAO/WHO Expert Committee on Food Additives. Geneva, Switzerland.

\footnotetext{
Kim D-H, Yoo H-S, Lee Y-M, Kie J-H, Jang S, Oh S. 2006. Elevation of sphinganine 1phosphate as a predictive biomarker for fumonisin exposure and toxicity in mice. $\mathrm{J}$ Toxicol Env Heal A. 69:2071-2082.
} 
Logrieco A, Moretti A., Ritieni A, Bottalico A, Corda P. 1995. Occurrence and toxigenicity of Fusarium proliferatum from preharvest maize ear rot, and associated mycotoxin, in Italy. Plant Dis. 79:727-731.

Marasas WFO. 1996. Fumonisins: History, world-wide occurrence and impact. Adv Exp Med Biol. 392:1-17.

Merrill AHJ, Wang E, Gilchrist DG, Riley RT. 1993. Advances in Lipid Research: Sphingolipids and Their Metabolites. Orlando: Academic Press. Fumonisins and other inhibitors of de novo sphingolipid biosynthesis; p. 215-234.

Merrill AH, Sweeley CC, 1996. Biochemistry of Lipids, Lipoproteins and Membranes. New York: Elsevier. Sphingolipids: metabolism and cell signaling; p. 43-73.

Merrill JAH, Sullards MC, Wang E, Voss KA, Riley RT. 2001. Sphingolipid metabolism: Roles in signal transduction and disruption by fumonisins. Environ Health Perspect. 109:283-289.

Morgan MK, Schroeder JJ, Rottinghaus GE, Powell DC, Bursian SJ, Aulerich RJ. 1997. Dietary fumonisins disrupt sphingolipid metabolism in mink and increase the free sphinganine to sphingosine ratio in urine but not in hair. Vet Hum Toxicol. 39:334-336. 
Nelson PE, Plattner RD, Shackelford DD, Desjardins AE. 1992. Fumonisin B 1 production by Fusarium species other than F. moniliforme in section Liseola and by some related species. Appl Environ Microbiol. 58:984-989.

Nikiema PA, Worrilow L, Traore AS, Wild CP, Turner PC. 2008. Fumonisin exposure and the sphinganine/sphingosine ratio in urine, serum and buccal cells in adults from Burkina Faso, West Africa. World Mycotox J. 1:483-491.

Norred WP, Plattner RD, Vesonder RF, Bacon CW, Voss KA. 1992. Effects of selected secondary metabolites of Fusarium moniliforme on unscheduled synthesis of DNA by rat primary hepatocytes. Food Chem Toxicol. 30:233-237.

Pascale M, Doko MB, Visconti A. 1995. Proceedings of the 2nd National Congress on Food Chemistry. Messina: La Grafica Editoriale. Determination of fumonisins in polenta by high performance liquid chromatography; p. 1067-1071.

Qiu M, Liu X. 2001. Determination of sphinganine, sphingosine and Sa/So ratio in urine of humans exposed to dietary fumonisin $B_{1}$. Food Addit Contam. 18:263-269.

Rheeder JP, Marasas WFO, Thiel PG, Sydenham EW, Shephard GS, Van Schalkwyk DJ. 1992. Fusarium moniliforme and fumonisins in corn in relation to human esophageal cancer in Transkei. Phytopathology 82:353-357. 
Riley RT, An NH, Showker JL, Yoo HS, Norred WP, Chamberlain WJ, Wang E, Merrill JAH, Motelin G, Beasley VR, et al. 1993. Alteration of tissue and serum sphinganine to sphingosine ratio: an early biomarker of exposure to fumonisin-containing feeds in pigs. Toxicol Appl Pharmacol. 118:105-112.

Riley RT, Enongen E, Voss KA, Norred WP, Meredith FI, Sharma RP, Williams D, Merrill AHJ. 2001. Sphingolipid perturbations as mechanisms for fumonisin carcinogenesis. Environ Health Perspect. 109:301-308.

Rossi M, Ancona E, Mastrangelo G, Solimbergo D, Paruzzolo P, Assarini G, Sorrentina P, Peracchia A. 1982. Epidemiologic findings in esophageal cancer in the Veneto region. Minerva Med. 73:1531-1540.

Sanchis V, Abadias M, Oncins L, Sala N, Viñas I, Canela R. 1994. Occurrence of fumonisins $\mathrm{B}_{1}$ and $\mathrm{B}_{2}$ in corn-based products from the Spanish market. Appl Environ Microbiol. 60:2147-2148.

Sanchis V, Abadias M, Oncins L, Sala N, Viñas I, Canela R. 1995. Fumonisins B $_{1}$ and $B_{2}$ and toxigenic Fusarium strains in feeds from the Spanish market. Int $\mathbf{J}$ Food Microbiol. $27: 37-44$.

Shephard GS, Thiel PG, Storckenstrom S, Sydenham EW. 1996. Worldwide survey of fumonisin contamination of corn and corn-based products. J AOAC Int. 79:671-687. 
Shephard GS, Van der Westhuizen L, Sewram V. 2007. Biomarkers of exposure to fumonisin mycotoxins: a review. Food Addit Contam. 24:1196-1201.

Silva LJG, Lino CM, Pena A. 2009. Sphinganine-sphingosine ratio in urine from two Portuguese populations as biomarker to fumonisins exposure. Toxicon 54:390-398.

Solfrizzo M, Chulze SN, Mallmann C, Visconti A, De Girolamo A, Rojo F, Torres A. 2004. Comparison of urinary sphingolipids in human populations with high and low maize consumption as a possible biomarker of fumonisin dietary exposure. Food Addit Contam. 21:1090-1095.

Sydenham EW, Thiel PG, Marasas WFO, Shephard GS, Schalkwyk DJ, Koch KR. 1990. Natural occurrence of some Fusarium mycotoxins in corn from low and high esophageal cancer prevalence areas of Transkei, Southern Africa. J Agric Food Chem. 38:19001903.

Torres MR, Sanchis V, Ramos AJ. 1998. Occurrence of fumonisins in Spanish beers analysed by an enzyme-linked immunosorbent assay method. Int $\mathbf{J}$ Food Microbiol. 39:139-143. 
Tran ST, Tardieu D, Auvergne A, Bailly JD, Babile R, Durand S, Benard G, Guerre P. 2006. Serum sphinganine and the sphinganine to sphingosine ratio as a biomarker of dietary fumonisins during chronic exposure in ducks. Chem Biol Interact. 160:41-50.

University of Lleida - Catalonian Food Security Agency (UdL-ACSA). 2009. Project to Assess the Exposure of Catalonian Population to the Mycotoxins. Internal Technical Report June 2009. Lleida. Applied Microbiology Group/ Food Technology Department/ University of Lleida. Supported by Catalonian Food Security Agency.

Van der Westhuizen L, Brown NL, Marasas WF, Swanevelde, S, Shephard GS. 1999. Sphinganine/sphingosine ratio in plasma and urine as a possible biomarker for fumonisin exposure in humans in rural areas of Africa. Food Chem Toxicol. 37:1153-1158.

\begin{abstract}
Van der Westhuizen L, Shephard GS, van Schalkwyk DJ. 2001. The effect of a single gavage dose of fumonisin $\mathrm{B}_{1}$ on the sphinganine and sphingosine levels in vervet monkeys. Toxicon 39:273-281.
\end{abstract}

\footnotetext{
Van der Westhuizen L, Shephard GS, Rheeder JP, Somdyala NIM, Marasas WFO. 2008. Sphingoid base levels in humans consuming fumonisin-contaminated maize in rural areas of the former Transkei, South Africa: A cross-sectional study. Food Addit Contam A 25:1385-1391.
} 
Van der Westhuizen L, Shephard GS, Rheeder JP, Burger H-M. 2010. Individual fumonisin exposure and sphingoid base levels in rural populations consuming maize in South Africa. Food Chem Toxicol. 48:1698-1703.

Velluti A, Marín S, Sanchis V, Ramos AJ. 2001. Note. Occurrence of fumonisin $B_{1}$ in Spanish corn-based foods for animal and human consumption. Food Sci Technol Int. $7: 433-437$

Visconti A, Doko MB, Solfrizzo M, Pascale M, Boenke A. 1996. European Intercomparison Study for the Determination of Fumonisins in Maize. Mikrochim Acta 123:55-61.

Voss KA, Riley R, Dunn C, Christopher Corton J. 2006. The role of tumor necrosis factor alpha and the peroxisome proliferator-activated receptor alpha in modulating the effects of fumonisin in mouse liver. Toxicology 222:165-74.

Wang E, Norred WP, Bacon CW, Riley RT, Merrill AHJ. 1991. Inhibition of sphingolipid biosynthesis by fumonisins: implications for diseases associated with Fusarium moniliforme. J Biol Chem. 266:14486-14490.

Wang E, Ross PF, Wilson TM, Riley RT, Merrill JAH. 1992. Increases in serum sphingosine and sphinganine and decreases in complex sphingolipids in ponies given feed 
containing fumonisins, mycotoxins produced by Fusarium moniliforme. J Nutr. 122:1706-1716.

Wang E, Riley RT, Meredith FI, Merrill JAH. 1999. Fumonisin B $_{1}$ consumption by rats causes reversible, dose-dependent increases in urinary sphinganine and sphingosine. $\mathbf{J}$ Nutr. 129:214-220.

Wang H, Wei H, Ma J, Luo X. 2000. The fumonisin B1 content in corn from North China, a high-risk area of esophageal cancer. J Environ Pathol Toxicol Oncol. 19:139_ 141.

Willett W. 1998. Nutritional Epidemiology. 2nd ed. New York: Oxford University Press.

Xu L, Cai Q, Tang L, Wang S, Hu X, Su J, Sun G, Wang J-S. 2010. Evaluation of fumonisin biomarkers in a cross-sectional study with two high-risk populations in China. Food Addit Contam A 27:1161-1169.

Yoo H-S, Norred WP, Showker JL, Riley RT. 1996. Elevated sphingoid bases and complex sphingolipid depletion as contributing factors in fumonisin-induced cytotoxicity. Toxicol Appl Pharmacol. 138:211-218. 
Yoshizawa T, Yamashita A, Luo Y. 1994. Fumonisin occurrence in corn from high- and low-risk areas for human esophageal cancer in China. Appl Environ Microbiol. 60:16261629.

Zhang H, Nagashima H, Goto T. 1997. Natural occurrence of mycotoxins in corn samples from high and low risk areas for human esophageal cancer in China. Mycotoxins 44:2935.

Zitomer NC, Mitchell T, Voss KA, Bondy GS, Pruett ST, Garnier-Amblard EC, Liebeskind LS, Park H, Wang E, Sullards MC, Merrill AHJ, Riley RT. 2009. Ceramide synthase inhibition by fumonisin B1 causes accumulation of 1-deoxysphinganine: a novel category of bioactive 1-deoxysphingoid bases and 1-deoxydihydroceramides biosynthesized by mammalian cell lines and animals. J Biol Chem. 284:4786-95. 
Table 1. Method performance characteristics for fumonisin $B_{1}$ and $B_{2}$

\begin{tabular}{|c|c|c|c|c|c|c|c|c|c|}
\hline \multirow{3}{*}{ Food Matrix } & \multicolumn{5}{|c|}{$\mathrm{FB}_{1}$} & \multicolumn{4}{|c|}{$\mathrm{FB}_{2}$} \\
\hline & $\mathrm{n}$ & LOD/LOQ & Spiked level & Recovery* & RSDr & LOD/LOD & Spiked level & Recovery & RSDr \\
\hline & & $\mu \mathrm{g} / \mathrm{kg}$ & $\mu \mathrm{g} / \mathrm{kg}$ & $\%$ & $\%$ & $\mu \mathrm{g} / \mathrm{kg}$ & $\mu \mathrm{g} / \mathrm{kg}$ & $\%$ & $\%$ \\
\hline Sweet Corn & 3 & $5.2 / 15.6$ & 266 & $101.5 \pm 11.8$ & 11.60 & $5.2 / 15.6$ & 133 & $104.0 \pm 7.3$ & 7.04 \\
\hline Corn Snacks & 3 & $5.2 / 15.6$ & 266 & $76.5 \pm 11.5$ & 15.01 & $5.2 / 15.6$ & 133 & $109.7 \pm 12.3$ & 11.30 \\
\hline Beer & 5 & $3.9 / 11.7$ & 200 & $93.0 \pm 14.0$ & 15.00 & $3.9 / 11.7$ & 100 & $108.0 \pm 10.0$ & 10.00 \\
\hline
\end{tabular}


Table 2. Method performance characteristics for sphingosine and sphinganine in plasma

\begin{tabular}{lrrrrr} 
& $\begin{array}{r}\text { LOQ/LOD } \\
\mathrm{ng} / \mathrm{mL}\end{array}$ & $\begin{array}{r}\text { Spiked level } \\
\mathrm{ng} / \mathrm{mL}\end{array}$ & $\mathrm{n}$ & $\begin{array}{r}\text { Recovery* } \\
\%\end{array}$ & $\begin{array}{r}\text { RSDr } \\
\%\end{array}$ \\
\hline Sphingosine & $0.15 / 0.048$ & 5 & 4 & $98.9 \pm 6.4$ & 6.4 \\
& $0.15 / 0.048$ & 20 & 4 & $92.2 \pm 19.7$ & 21.3 \\
& $0.15 / 0.048$ & 40 & 4 & $104.0 \pm 12.8$ & 12.3 \\
\hline Sphinganine & $0.14 / 0.047$ & 2.5 & 4 & $96.8 \pm 9.7$ & 9.3 \\
& $0.14 / 0.047$ & 12 & 4 & $98.3 \pm 11.2$ & 11.4 \\
& $0.14 / 0.047$ & 24 & 4 & $93.1 \pm 13.4$ & 14.3 \\
\hline
\end{tabular}

*: Mean \pm Standard Deviation 
Table 3. Method performance characteristics for sphingosine and sphinganine in urine

\begin{tabular}{lrrrrr} 
& $\begin{array}{r}\text { LOD } \\
\mathrm{ng} / \mathrm{mL}\end{array}$ & $\begin{array}{r}\text { Spiked level } \\
\mathrm{ng} / \mathrm{mL}\end{array}$ & $\mathrm{n}$ & $\begin{array}{r}\text { Recovery* } \\
\%\end{array}$ & $\begin{array}{r}\text { RSDr } \\
\%\end{array}$ \\
\hline Sphingosine & 0.04 & 5 & 5 & $122.9 \pm 5.5$ & 4.5 \\
& 0.04 & 40 & 5 & $126.9 \pm 18.2$ & 14.4 \\
\hline Sphinganine & 0.02 & 5 & 5 & $107.6 \pm 5.6$ & 5.2 \\
& 0.02 & 40 & 5 & $104.3 \pm 9.3$ & 8.9 \\
\hline
\end{tabular}

*: Mean \pm Standard Deviation 
Table 4. Sphinganine (Sa) and sphingosine (So) levels in urine and plasma, and the Sa/So ratio in population from Catalonia (Spain), from the cross-sectional studies.

\begin{tabular}{|c|c|c|c|c|c|}
\hline Group & $\mathrm{n}$ & $\begin{array}{l}\text { nisin intake } \\
\mathrm{g} / \mathrm{kg} \text { bw/day }\end{array}$ & $\begin{array}{r}\mathrm{Sa}^{*} \\
\mathrm{ng} / \mathrm{mL} \\
\end{array}$ & $\begin{array}{r}\text { So* } \\
\mathrm{ng} / \mathrm{mL} \\
\end{array}$ & $\begin{array}{r}\text { Ratio* } \\
\text { Sa/So } \\
\end{array}$ \\
\hline \multicolumn{6}{|l|}{ Levels in urine } \\
\hline Low and non consumers & 43 & $0.02 \pm 0.02$ & $0.38(0.95 \pm 2.15)^{\mathrm{A}}$ & $0.83(2.57 \pm 5.02)^{\mathrm{A}}$ & $0.40(0.55 \pm 0.47)^{\mathrm{A}}$ \\
\hline Consumers & 35 & $0.14 \pm 0.83$ & $0.26(1.29 \pm 2.15)^{\mathrm{A}}$ & $0.57(2.59 \pm 0.85)^{\mathrm{A}}$ & $0.56(0.62 \pm 0.47)^{\mathrm{B}}$ \\
\hline \multicolumn{6}{|l|}{ Levels in plasma } \\
\hline Non consumers & 68 & 0.00 & $4.12(6.5 \pm 9.2)^{\mathrm{A}}$ & $8.51(14.3 \pm 16.5)^{\mathrm{A}}$ & $0.46(0.45 \pm 0.12)^{\mathrm{A}}$ \\
\hline Consumers & 68 & $0.23 \pm 0.11$ & $3.14(4.1 \pm 3.6)^{\mathrm{A}}$ & $5.89(7.8 \pm 6.8)^{\mathrm{B}}$ & $0.53(0.54 \pm 0.16)^{\mathrm{B}}$ \\
\hline
\end{tabular}

*Median (Mean \pm Standard Deviation).

(A) Capital letter: different letters mean significant differences between groups, when we compare non consumers with consumers $(P<0.05$; Mann-Whitney $U$ test) 
Table 5. Time-course of median sphinganine and sphingosine levels, and Sa/So ratios (in ng/mL).

\begin{tabular}{|c|c|c|c|c|c|c|}
\hline Ratio Sa/So & Day -7 & Day 0 & Day 1 & Day 4 & Day 6 & Day 8 \\
\hline Control & $0.25^{\mathrm{aA}}$ & $0.62^{\mathrm{aA}}$ & & $0.52^{\mathrm{aA}}$ & & $0.45^{\mathrm{aA}}$ \\
\hline Low exposed & $0.70^{\mathrm{aAB}}$ & $0.26^{\mathrm{bA}}$ & $0.27^{\mathrm{aAB}}$ & $1.10^{\mathrm{abB}}$ & $0.43^{\mathrm{aA}}$ & $0.47^{\mathrm{aA}}$ \\
\hline High Exposed & $0.51^{\mathrm{aA}}$ & $0.39^{\mathrm{abA}}$ & $0.80^{\mathrm{aA}}$ & $2.43^{\mathrm{bB}}$ & $0.98^{\mathrm{bAB}}$ & $0.45^{\mathrm{aAB}}$ \\
\hline \multicolumn{7}{|l|}{ Sphingosine } \\
\hline Control & $1.23^{\mathrm{aA}}$ & $0.53^{\mathrm{aA}}$ & & $0.30^{\mathrm{aA}}$ & & $0.21^{\mathrm{aA}}$ \\
\hline Low exposed & $0.68^{\mathrm{aA}}$ & $0.45^{\mathrm{aA}}$ & $0.36^{\mathrm{aA}}$ & $0.19^{\mathrm{aA}}$ & $0.28^{\mathrm{aA}}$ & $0.32^{\mathrm{aA}}$ \\
\hline High Exposed & $0.33^{\mathrm{aA}}$ & $0.20^{\mathrm{aA}}$ & $0.15^{\mathrm{aA}}$ & $0.08^{\mathrm{aA}}$ & $0.12^{\mathrm{aA}}$ & $0.31^{\mathrm{aA}}$ \\
\hline \multicolumn{7}{|l|}{ Sphinganine } \\
\hline Control & $0.27^{\mathrm{aA}}$ & $0.14^{\mathrm{aA}}$ & & $0.12^{\mathrm{aA}}$ & & $0.16^{\mathrm{aA}}$ \\
\hline Low Exposed & $0.28^{\mathrm{aA}}$ & $0.13^{\mathrm{aA}}$ & $0.12^{\mathrm{aA}}$ & $0.24^{\mathrm{aA}}$ & $0.19^{\mathrm{aA}}$ & $0.15^{\mathrm{aA}}$ \\
\hline High Exposed & $0.14^{\mathrm{aA}}$ & $0.10^{\mathrm{aA}}$ & $0.19^{\mathrm{aA}}$ & $0.19^{\mathrm{aA}}$ & $0.12^{\mathrm{aA}}$ & $0.16^{\mathrm{aA}}$ \\
\hline
\end{tabular}

Control group (non consumers), Low exposed (<0.6 $\mu \mathrm{g} / \mathrm{kg}$ bw/day), High exposed ( $>0.6 \mu \mathrm{g} / \mathrm{kg}$ bw/day).

(A) Capital letter: in each row, different letters mean significant differences among days $(P<0.05$, Kruskal-Wallis test $)$

(a) Lower case letter: in each column, for each category, different letters mean significant differences between groups $(P<0.05$, Kruskal-Wallis test) 
Table 6. Absolute variation of sphinganine and sphingosine urinary levels from volunteers under restricted conditions, variation was accounted between day 0 and day 8 (in $\mathrm{ng} / \mathrm{mL}$ ).

\begin{tabular}{|c|c|c|c|c|c|c|c|c|c|}
\hline \multirow[t]{2}{*}{ Group } & \multicolumn{3}{|l|}{$\mathrm{Sa}$} & \multicolumn{3}{|l|}{ So } & \multicolumn{3}{|l|}{$\mathrm{Sa} / \mathrm{So}$} \\
\hline & $\max$ & $\min$ & median (mean \pm sd) & $\max$ & $\min$ & median (mean \pm sd) & $\max$ & $\min$ & median $($ mean \pm sd) \\
\hline Control & 1.30 & 0.02 & $0.17(0.27 \pm 0.35)^{\mathrm{a}}$ & 2.31 & 0.01 & $0.28(0.56 \pm 0.67)^{\mathrm{a}}$ & 1.76 & 0.09 & $0.96(0.90 \pm 0.55)^{\mathrm{a}}$ \\
\hline Low Exposed & 0.62 & 0.11 & $0.23(0.28 \pm 0.18)^{\mathrm{a}}$ & 1.77 & 0.10 & $0.81(0.83 \pm 0.51)^{\mathrm{a}}$ & 7.56 & 0.12 & $0.98(2.09 \pm 2.65)^{\mathrm{a}}$ \\
\hline High Exposed & 0.80 & 0.10 & $0.15(0.26 \pm 0.22)^{\mathrm{a}}$ & 1.69 & 0.08 & $0.27(0.45 \pm 0.48)^{\mathrm{a}}$ & 6.56 & 0.44 & $1.06(2.73 \pm 2.32)^{\mathrm{a}}$ \\
\hline
\end{tabular}


Figure 1.

Title: Diagram of urine sampling design and restriction periods performed in the study to assess urinary Sa and So time-course.

Footnote: US: urine sample, R24: 24 hours record, FFQ: Food Frequency Questionnaire $1418 \times 1064 \mathrm{~mm}(55 \times 55 \mathrm{DPI})$ 
1

2

3

4

5

6

7

8

9

10

11

12

13

14

15

16

17

18

19

20

21

22

23

24

25

26

27

28

29

30

31

32

33

34

35

36

37

38

39

40

41

42

43

44

45

46

47

48

49

50

51

52

53

54

55

56

57

58

59

60

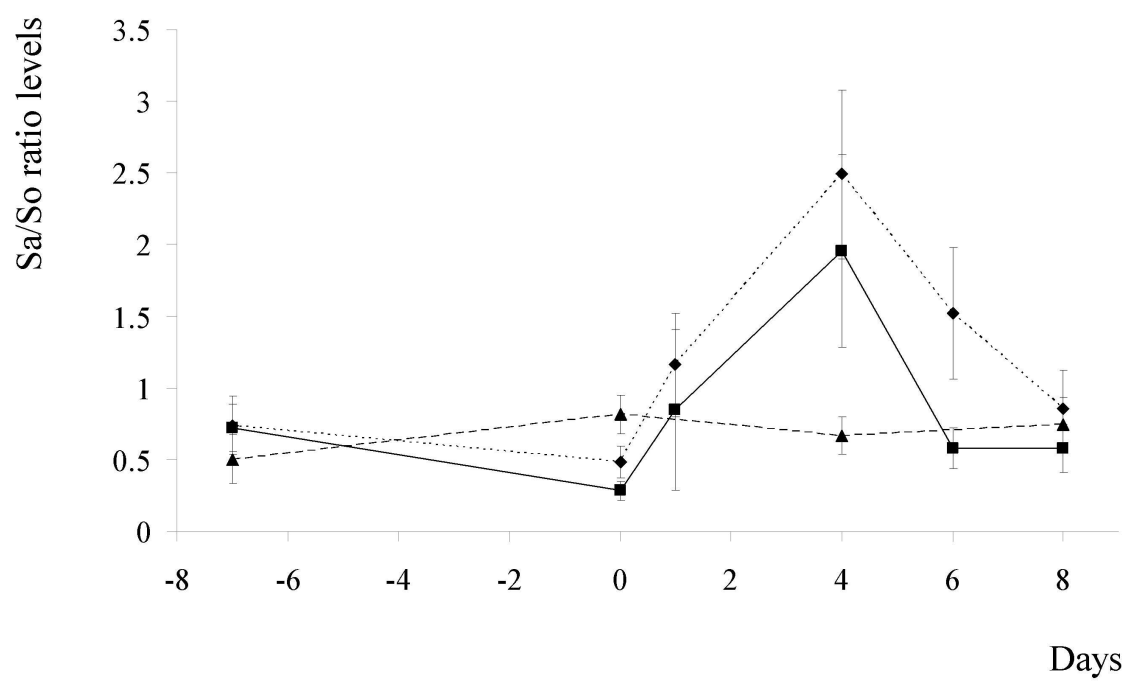

Figure 2

Title: Time-course of mean Sa/So ratio for high exposed $(H, \quad)$, low exposed $(L, \quad)$ and non exposed (C, ).

$1418 \times 958 \mathrm{~mm}(55 \times 55$ DPI) 


\section{Figure Captions}

\section{Figure 1}

Title: Diagram of urine sampling design and restriction periods performed in the study to assess urinary Sa and So time-course.

Footnote: US: urine sample, R24: 24 hours record, FFQ: Food Frequency Questionnaire

Figure 2

Title: Time-course of mean Sa/So ratio for high exposed $(\mathrm{H}, \cdots \bullet \cdot)$, low exposed $(\mathrm{L}, \rightarrow-\mathbf{}$ and non exposed $\left(\mathrm{C},-\boldsymbol{\star}^{-}\right)$. 